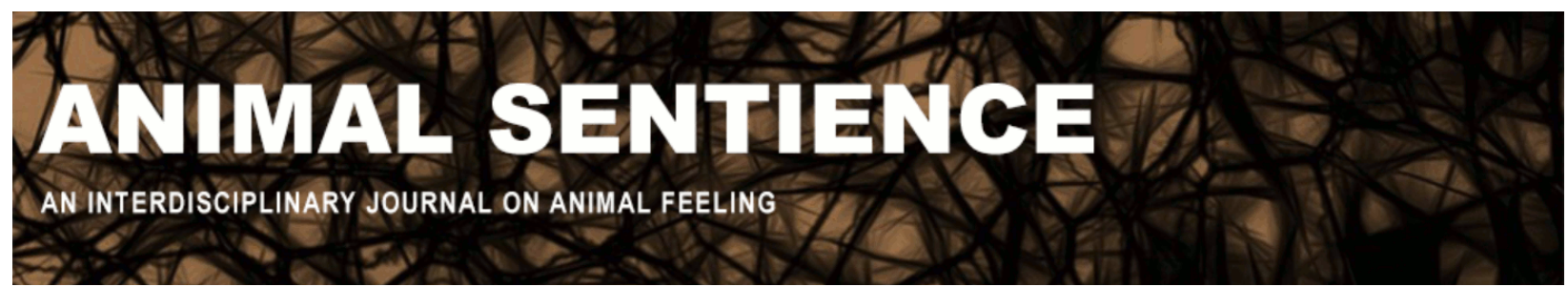

Mallatt, Jon (2017) Shoring up the precautionary BAR. Animal Sentience 16(7) DOI: $10.51291 / 2377-7478.1229$

Date of submission: $2017-10-18$

Date of acceptance: $2017-10-24$

(c) (i)




\title{
Shoring up the precautionary BAR
}

Commentary on Birch on Precautionary Principle

\author{
Jon Mallatt \\ WWAMI Medical Education Program \\ University of Idaho
}

\begin{abstract}
I offer four ways to reinforce Birch's precautionary principle so it can be used effectively and practically in deciding which animals to cover by legislation for humane treatment: (1) add one more credible indicator of sentience to the BAR rule; (2) use phylogenetic classification, not the outdated Linnaean classification, to test which animal clades have sentience; (3) disentangle the pain of suffering from sentience; and (4) reconsider the sentient status of decapods and insects to remove potential inconsistencies in the proposed framework.
\end{abstract}

Jon M. Mallatt is Clinical Associate Professor in the WWAMI Medical Education Program of the University of Washington at the University of Idaho. His research is on the origin of the major animal groups, especially vertebrates, as well as the evolutionary origin of consciousness.

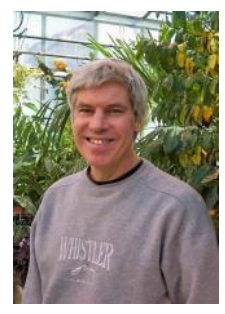

Jonathon Birch's (2017) target article on the precautionary principal is a good contribution to the literature on animal sentience. It should have a positive effect on legislative policies for protecting animals. The writing style is excellent; the logic is clear; and although I am not an ethicist or an expert on animal-protection issues, I found the central proposal to be well reasoned and argued. That proposal was to set a rather low bar for judging which animals are sentient so that regulators can act in a precautionary way to decide which animal clades to protect so as to minimize the chance of causing pain. Birch has met his goals of clarifying how the precautionary principle should be applied to animals, and of making it more precise and practical. The list of behavioral criteria he used on p. 7 to judge whether animals have sentient feelings of attraction (positive affect) or aversion (negative affect) is well supported by the literature, so it is solid. However, I wish he had put more emphasis on the learning criteria, namely on the capacity for operant learning from reward and punishment, plus the new, ramped-up version of this, called unlimited associative learning (UAL: Bronfman et al. 2016), in which the initially rewarded learning can lead to more and more learning. UAL seems to be a very good indicator of whether an animal is sentient.

Birch's proposal will help to correct some of the weaknesses of past investigations into whether fish and invertebrates feel pain. These weaknesses, as pointed out by Rose et al. (2014) and Feinberg and Mallatt (2016), are as follows:

1. High ratios of anecdotal-to-experimental evidence.

2. The experiments often did not distinguish nonconscious nociception from conscious pain. 
3. Not enough recognition that sharp short-term pain differs from dull long-term pain - a problem, because only the latter type of pain is the basis of the suffering with which animalprotection advocates are most concerned.

4. Past studies missed evolutionary indications that only some animals have the suffering type of pain (those animals that can hide for a long time while healing) whereas others do not (animals that live in the open, exposed to predators that can spot the weakness of a suffering prey) (Bolles and Faneslow 1980; Crook and Walters 2014); this implies that short-term pain is more common in the animal kingdom than is the long-term suffering that raises the most concern.

5. The behavioral studies of animal pain continue to dominate over the neurobiological (anatomical and physiological) studies of pain pathways. The neurobiological studies are just as informative but are few in number - and even seem to be decreasing for the very animals being considered for continued or new protection, namely, the non-bony fishes, decapod crustaceans, and the other arthropods.

From among these problems, Birch has recognized and insisted that nociception must be distinguished from pain, that experiments must follow the highest scientific standards, and that neurobiological as well as behavioral studies are needed. Thus, his guidelines can considerably improve future studies of animal pain.

Also praiseworthy is his insistence that to be credible, any indicator of sentience in an animal group must be "an observable phenomenon that experiments can be designed to detect." This acknowledges the principle, championed by the philosopher of science Karl Popper, that scientific hypotheses must be testable and falsifiable (Popper 1959). Birch presents the falsifiability criterion by saying the indicator must be subject to constant review, revision, and updating. If applied to regulatory policy, this will allay the political concerns of those who fear that once a clade is protected by legislation, it can never be de-listed even if subsequently proven to be non-sentient.

I like Birch's practicality. He acknowledges that financial costs should be considered and that animals with lower-level sentience may receive less legislative protection than animals with higher-level sentience. He says these two levels of sentience are difficult to distinguish or define but I would call them, respectively, primary consciousness (raw experience without any reflection) and memory-enhanced consciousness (long memory of past experiences and some reflection). These levels are explained in the Feinberg and Mallatt (2016) book.

I should emphasize that I am talking about practicality and political reality, not ethics. I am on record as saying that insects have primary consciousness and are sentient (Mallatt and Feinberg 2016). By practicality, I mean only that I recognize the near impossibility of any legislation being passed to protect the many million gnats and horse flies in the foreseeable future.

The rest of this commentary is devoted to my suggestions for improving Birch's proposal. His proposed BAR rule says that "one credible indicator of sentience is enough to justify action: we should not demand multiple indicators before acting to protect the animals concerned." His rationale for using only one is that requiring more indicators "will have the effect of further delaying action, and the purpose of a precautionary principle is to prevent such delays."

To me as a scientist, one indicator is not enough. Scientists are trained to seek multiple lines of evidence and counter-evidence, weighed and then debated, in order to come to a credible decision. What happens to the BAR when a hypothesis is supported by one credible indicator, but 
another credible indicator speaks against it? This is exactly the problem for the decapod crustaceans (e.g., crabs), which are heavily spotlighted in Birch's essay. Decapods pass the behavioral tests for sentience, as Birch documents, but they have a paltry 100,000 neurons in their entire nervous system, which indicates they are not sentient (Fraser 2009). All the vertebrates, by contrast, have millions of neurons. Decapods' 100,000 neurons are even fewer than in most insects, a group that also passes all the behavioral tests but that Birch does not consider sentient. My studies with Todd Feinberg uncovered evidence that decapods and insects are indeed sentient (Mallatt and Feinberg 2016), with insects just lacking some aspects of pain (Adamo 2016, p. 76). But that is not the point. The point is that using just one line of evidence is insufficient and may even amount to the lowering of scientific standards that Birch wants to avoid.

How to solve it? I understand why Birch designed BAR to require just one indicator, namely, to speed up the path to regulatory action because delay could mean more animals keep suffering from fisheries and in science labs. That is a valid concern. To minimize the added delay, I propose that just one more credible indicator be added to the BAR, for a total of two. The two indicators should be largely independent, usually one that is neurobiological and one that is behavioral, but that lead to the same conclusion from two different directions (and are not countered by a lot of opposing evidence). This will raise the "effort BAR," but not by too much. Any extra effort and time needed to obtain the evidence for the second indicator will be more than offset by jettisoning the burdensome guideline that every order of animals be tested (next section).

The BAR criterion uses the traditional, Linnaean classification system as it proposes testing sentience in at least one animal species per order. This raises many problems. First, it would require a lot of animal testing, given the $>60$ traditional orders of fish, $\sim 26$ orders of mammals, $>20$ of insects, $>100$ of molluscs, $>25$ of nematode roundworms, etc. Birch recognizes this burden and offers a way to lessen the effort: focus on the most exploited orders of animals. But a better goal would be to find all the conscious animals without having to test so many. Second, because the higher Linnaean categories are subjective constructs, the orders of different animals are not necessarily comparable: A mollusc "order" may have a lot less or a lot more animal diversity than a mammal "order" (Brusca and Brusca 2003). The third problem is that the traditional categories are considered outdated; so if the BAR rule uses them, it will lack credibility among modern biologists.

There is an easy way for BAR to remove its dependence on "orders," and solve all the problems. It can switch to a modern phylogenetic classification scheme that only names clades (a clade is a group of taxa that share a common ancestor) and allows the reconstruction of characters that were present in the ancestor of the clade. [See the Wikipedia entries on ancestral reconstruction and phylogenetics.] This means "sentience" can be chosen as the character of interest and charting its presence (or absence) in a mere fraction of the end-clades is often enough to calculate whether it was present in the ancestor at the base of the clade (in the first decapods, the first vertebrates, or first cephalopods, for example). Some of the models used to reconstruct ancestral characters are complex, but others are quite simple, especially those that use big characters like sentience. The program PAUP* (Swofford 1998), which is based on a model called maximum parsimony, is appropriate and quite easy to use (Mallatt and Chen 2003). By changing the BAR rule to include phylogenetic reconstruction, the many tedious experiments and brain studies on hundreds of animal "orders" won't be necessary, saving much time. 
Even easier, one could just study the existing hypotheses about which animals are sentient (conscious) and then use reason to evaluate those hypotheses and modify them based on any new evidence. For example, Todd Feinberg and I constructed lists of criteria for sentience and the animals that fit them (Feinberg and Mallatt 2016; Mallatt and Feinberg 2016). We deduced that the sentient animals are all the vertebrates, all arthropods, and the octopus-squid-cuttlefish clade of cephalopod molluscs. One need not agree with this deduction but can still use our list as a springboard from which to reason out one's own clades of sentient animals. Then, normal scientific debate could lead to a majority agreement, if not a consensus. There is hope that a new consensus could emerge, as belief in the long-held view that consciousness exists only in mammals (and birds) has faded in the past ten years (Cambridge Declaration on Consciousness, 2012; Boly et al. 2013; Klein and Barron 2016; Birch 2017).

Those who empathize with animals do not want them to be hurt, so it is natural that animal sentience is so often equated with the capacity to suffer pain. But this suffering-centered view misses the possibility that some animals could experience negative affects (bad feelings) but little or no suffering/pain. Many fish, antelopes, and insects could be in this group. But negative affects, from continual discomfort to repeated short-term pain to prolonged fear, can feel quite awful even in the absence of suffering/pain. Inducing "misery" like this is also inhumane treatment, against which sentient animals should be protected. Pain is not everything when it comes to sentience. This means that more animals could come under protection, not fewer: all animals that can feel negative affects would be included whether they feel certain types of pain or not.

Birch is not to be faulted for missing the possibility that sentience can exist in animals that do not suffer pain - almost no one else considers it either. However, the distinction has implications for Birch's thesis. It implies that he dismisses insect sentience (fruit flies) too hastily. And it provides an answer to the final request in his paper, for help in answering whether the jawless fish (lampreys and hagfish) and the cartilaginous fish are sentient. I assume his uncertainty stemmed from these fish lacking the sensory " $C$ " fibers for long-term, suffering pain (table 8.4 in Feinberg and Mallatt 2016). Yet other evidence says that though not "long-suffering," they are indeed sentient. The jawless and cartilaginous fish have many "limbic" structures in their brains, structures associated with sentient affects in all the other vertebrates (table 8.5 and p. 155 in Feinberg and Mallatt 2016). And the cartilaginous sharks and their kin learn readily from reward and punishment in operant conditioning (Guttridge et al. 2009), which is another sign of affect.

In summary, Birch presents a helpful and practical framework for applying the precautionary principle to animal welfare. As he requested, I suggest these four improvements: add one more credible indicator of sentience to the BAR rule, for a total of two; use phylogenetic classification, not the outdated Linnaean classification, to test which animal clades have sentience; disentangle the pain of suffering from sentience; and reconsider the sentient status of decapods and insects to remove potential inconsistencies in the proposed framework. 


\section{References}

Adamo, S. A. (2016). Do insects feel pain? A question at the intersection of animal behaviour, philosophy and robotics. Animal Behaviour 118:75-79.

Birch, J. (2017). Animal sentience and the precautionary principle. Animal Sentience 16(1).

Bolles, R.C. and Faneslow, M.S. (1980). A perceptual-defensive-recuperative model of fear and pain. Behavioral and Brain Sciences 3:291-323.

Boly, M., Seth, A. K., Wilke, M., Ingmundson, P., Baars, B., Laureys, S., Edelman, D.B. and Tsuchiya, N. (2013). Consciousness in humans and non-human animals: recent advances and future directions. Frontiers in Psychology 4:625.

Bronfman, Z. Z., Ginsburg, S. and Jablonka, E. (2016). The transition to minimal consciousness through the evolution of associative learning. Frontiers in Psychology 7.

Brusca, R.C. and Brusca, G.J. (2003). Invertebrates. $2^{\text {nd }}$ edition. Sunderland, MA: Sinuaer Associates.

Crook, R. J. and Walters, E. T. (2014). Neuroethology: self-recognition helps octopuses avoid entanglement. Current Biology 24(11):R520-R521.

Feinberg, T.E. and Mallatt, J. (2016a). The Ancient Origins of Consciousness. How the Brain Created Experience. Cambridge, MA: MIT Press.

Fraser, P. (2009). Do crabs have rights? New Scientist 203(2716): 24-25.

Guttridge, T.L., Myrberg, A.A., Porcher, I.F., Sims, D.W. and Krause, J. (2009). The role of learning in shark behaviour. Fish and Fisheries 10 (4): 450-469.

Klein, C. and Barron, A. B. (2016). Insects have the capacity for subjective experience. Animal Sentience 9(1).

Mallatt, J. and Chen, J.-Y. (2003). Fossil sister group of craniates: Predicted and found. Journal of Morphology 258(1):1-31.

Mallatt, J. and Feinberg, T. E. (2016). Insect consciousness: Fine-tuning the hypothesis. Animal Sentience 9(10).

Popper, K. (1959). The Logic of Scientific Discovery. London: Hutchinson \& Co.

Rose, J. D., Arlinghaus, R., Cooke, S. J., Diggles, B. K., Sawynok, W., Stevens, E. D. and Wynne, C. D. L. (2014). Can fish really feel pain? Fish and Fisheries 15(1):97-133.

Swofford, D.L. (1995). PAUP*. Phylogenetic Analysis Using Parsimony (* and Other Methods). Version 4.0b10a. Sunderland, MA: Sinauer Associates. 


\section{ANIMAL CONSCIOUSNESS}

On November 17-18, 2017, the NYU Center for Mind, Brain and Consciousness, the NYU Center for Bioethics, and NYU Animal Studies will host a conference on Animal Consciousness.

This conference will bring together philosophers and scientists to discuss questions such as: Are invertebrates conscious? Do fish feel pain? Are non-human mammals self-conscious? How did consciousness evolve? How does research on animal consciousness affect the ethical treatment of animals? What is the impact of issues about animal consciousness on theories of consciousness and vice versa? What are the best methods for assessing consciousness in non-human animals?

Speakers and panelists include:

Colin Allen (University of Pittsburgh, Department of History \& Philosophy of Science), Andrew Barron (Macquarie, Cognitive Neuroethology),

Victoria Braithwaite (Penn State, Biology), Peter Carruthers (Maryland,

Philosophy), Marian Dawkins (Oxford, Zoology), Dan Dennett (Tufts,

Philosophy), David Edelman (San Diego, Neuroscience),

Todd Feinberg (Mt. Sinai, Neurology), Peter Godfey-Smith (Sydney,

Philosophy), Lori Gruen (Wesleyan, Philosophy), Brian Hare (Duke, Evolutionary Anthropology), Stevan Harnad (Montreal, Cognitive Science), Eva Jablonka (Tel

Aviv, Cohn Institute), Björn Merker (Neuroscience), Diana Reiss (Hunter,

Psychology), Peter Singer (Princeton, Philosophy), Michael Tye (Texas, Philosophy)

Organizers: Ned Block, David Chalmers, Dale Jamieson, S. Matthew Liao.

The conference will run from 9am on Friday November 17 to $6 \mathrm{pm}$ on Saturday November 18 at the NYU Cantor Film Center (36 E 8th St).

Friday sessions will include "Invertebrates and the evolution of consciousness", "Do fish feel pain?", and "Animal consciousness and ethics".

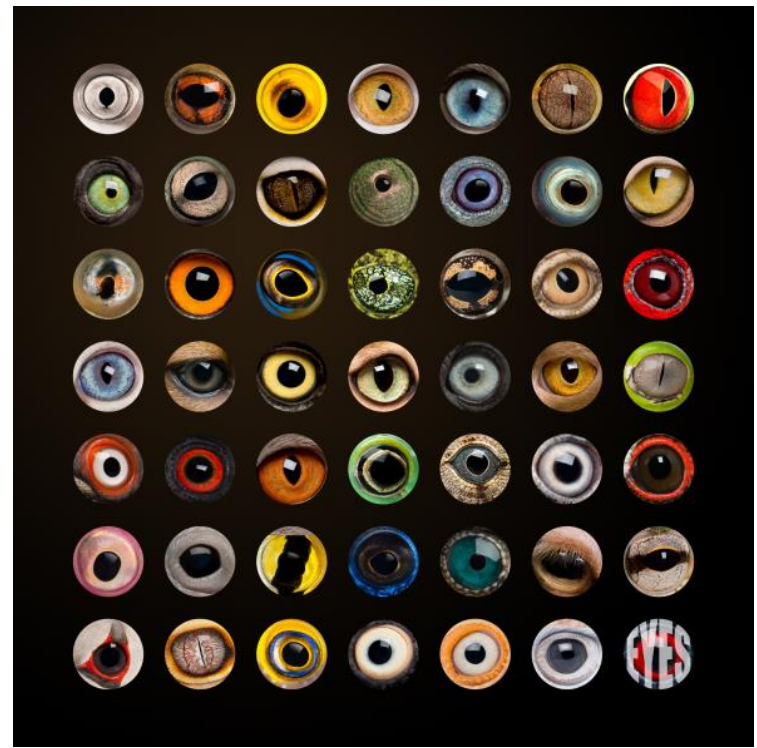

Saturday sessions will include "Animal self-consciousness", "Animal consciousness and theories of consciousness", and a panel discussion.

A detailed schedule will be circulated closer to the conference date.

Registration is free but required.

\section{Register here.}

\section{See also the conference website}

